\title{
IMAGENS DE UMA PAISAGEM EM TRANSFORMAÇÃO: A EXPLORAÇÃO MADEIREIRA EM PINHALZINHO-SC ENTRE AS DÉCADAS DE 1940 A 1970
}

Andressa Krieser Bauermann ${ }^{1}$ Marlon Brandt ${ }^{2}$

Resumo: O município de Pinhalzinho-SC foi colonizado por migrantes gaúchos principalmente de origem alemã, desde a década de 1930. É também, a partir desse período, que a região passou a receber a atuação de empresas madeireiras. Estas converteram espaços antes dominados pela floresta em terras destinadas à exploração agrícola e a produção de suínos, e posteriormente a atividades do setor comercial e industrial. Nesta perspectiva, o artigo objetiva analisar as transformações da paisagem no município de Pinhalzinho através da exploração madeireira entre os anos de 1940 a 1970 por meio de fotografias, abordando assim, a paisagem como um documento. Para tanto, num primeiro momento, por meio de um breve aporte teórico, abordamos o conceito de paisagem. Num segundo momento, discutimos a exploração madeireira e transformação da paisagem em Pinhalzinho, no recorte temporal proposto, como uma construção da ideologia do progresso. Para finalizar, apresentamos as considerações finais.

Palavras-chave: Paisagem. Pinhalzinho. História ambiental. Empresas madeireiras.

\section{IMAGES OF A LANDSCAPE IN TRANSFORMATION: THE WOOD EXPLORATION IN PINHALZINHO- SC BETWEEN THE DECADES OF 1940 TO 1970}

\begin{abstract}
The municipality of Pinhalzinho, located in the state of Santa Catarina was colonized by the 30's decade by Southern migrants, most of them descendants of German people. Also around the thirties, the region began to receive the activity of timber companies. These, turned the space into formerly forest-dominated areas, into farmlands, pig production lands and later, into commercial and industrial activities lands. In this perspective, the article aims do analyze the transformations of the landscape in the municipality of Pinhalzinho through logging between the years of 1940 to 1970 by of photographs thus approaching the landscape as a document. For this, in the first moment, through a theoretical brie contribution, we approach the concept of landscape. In the second moment, we discussed the logging and transformation of the landscape in Pinhalzinhoin the proposed temporal cut, as a construction of the ideology of progress. Finally, we present the final considerations.
\end{abstract}

Keywords: Landscape. Pinhalzinho. Environmental history. Timber companies.

\footnotetext{
'Universidade Estadual do Oeste do Paraná, Departamento de Geografia, Francisco Beltrão, Brasil, andressakrieserbauermann@gmail.com, https://orcid.org/0000-0001-8614-7502.

2Universidade Federal da Fronteira Sul, Programa de Pós-Graduação em Geografia e Programa de Pós-Graduação em História, Chapecó, Brasil, marlon.brandt@uffs.edu.br, https://orcid.org/0000-00020392-4167.
} 


\section{IMÁJENES DE UN PAISAJE EN TRANSFORMACIÓN: LA EXPLOTACIÓN MADERERA EN PINHALZINHO - SC ENTRE LAS DÉCADAS DE 1940 HASTA 1970}

Resumen: El municipio de Pinhalzinho - SC fue colonizado por los migrantes gauchos, principalmente con orígenes alemanas, desde la década de 1930. Es también, desde este periodo, que la región pasó a recibir la actuación de empresas madereras. Estas empresas han convertido espacios, antes dominados por las florestas, en tierras destinadas a la explotación agrícola y la producción de cerdos y, posteriormente, a las actividades del sector comercial e industrial. En esta perspectiva, este artículo tiene como objetivo analizar las transformaciones del paisaje del municipio de Pinhalzinho a través de la explotación maderera entre los años de 1940 hasta 1970 por medio de fotografías, abordando así, el paisaje como un documento. Para tanto, en un primer momento, por intermedio de un breve desarrollo teórico, el enfoque será el concepto de paisaje. En secuencia, discutiremos la explotación maderera y la transformación del paisaje en Pinhalzinho, en el recorte temporal propuesto, como una construcción de la ideología del progreso. Para encerrar, las consideraciones finales serán presentadas.

Palabras-clave: Paisaje. Pinhalzinho. Historia ambiental. Empresas madereras.

\section{Introdução}

Fazer uso da paisagem como documento, enquanto categoria de análise das relações entre os homens e a natureza, integra as características e os elementos físicos e humanos do passado e suas heranças no presente. Essa análise permite compreender que o espaço geográfico está em constante transformação à medida que todas as relações somente podem ocorrer no espaço e a partir do espaço.

Muitas dessas transformações no passado ficaram registradas através do uso de fotografias, nas quais aparece, intencionalmente ou como fundo, o espaço circundante. Essa fração congelada do tempo e do espaço, se trabalhada adequadamente não somente como mera ilustração, é uma importante fonte a ser incorporada nos estudos geográficos para avaliar a dinâmica socioespacial de uma região. Ao longo do período de colonização do Oeste, essas imagens produzidas por colonos, colonizadores e empresas madeireiras que aportaram a partir de então, retrataram, em sua maioria, a formação de lavouras, seus animais, a floresta derrubada e demais atividades econômicas ligadas a colonização. Ao se interpretar as imagens produzidas pode-se, nas palavras de Marcos Gerhardt (2005, p. 78), "conhecer parte das mudanças e permanências no ambiente daquele período e também a compreensão da população da época sobre a natureza, especificamente sobre o mato", ou seja, a paisagem que os circundava.

Ao se analisar a paisagem como um documento por meio de imagens, precisa-se entender que o autor da fotografia está fazendo uma cópia, e não 
criando, como em uma pintura. A imagem fotográfica é construída a partir da focalização, enquadramento e perspectiva do fotógrafo e este, ao produzir a imagem imprime/registra também suas construções de verdade, ou seja, tudo o que contribuiu para sua construção como sujeito. Portanto, este fotógrafo/sujeito, historicamente construído, ao determinar a temática de suas fotografias, está fazendo uma escolha. Assim, a fotografia não é apenas a emanação do referente, mas a emanação de um referente previamente escolhido, enquadrado, focalizado (ZENDRON, 2002, p. 87).

E são as imagens o objeto desse artigo, que procura analisar, por meio delas e sob um viés histórico-geográfico, as transformações da paisagem, tendo por recorte temporal a exploração madeireira no município de Pinhalzinho ao longo dos anos de 1940 a 1970.

Num primeiro momento, Pinhalzinho era pertencente ao município de Chapecó, cuja jurisdição estendia-se por todo o Oeste Catarinense. Posteriormente, passou a pertencer ao município de São Carlos, até então centro urbano mais próximo, elevando-se a distrito pela Lei Municipal no 30, de 12-05-1956. Sua emancipação, mantendo a mesma denominação, ocorreu pela Lei Estadual ํㅜ 780, de 07-12-1961 ${ }^{3}$. A localização de Pinhalzinho, pode ser observada no Mapa 1. 
Mapa 1 - Localização do município de Pinhalzinho-SC

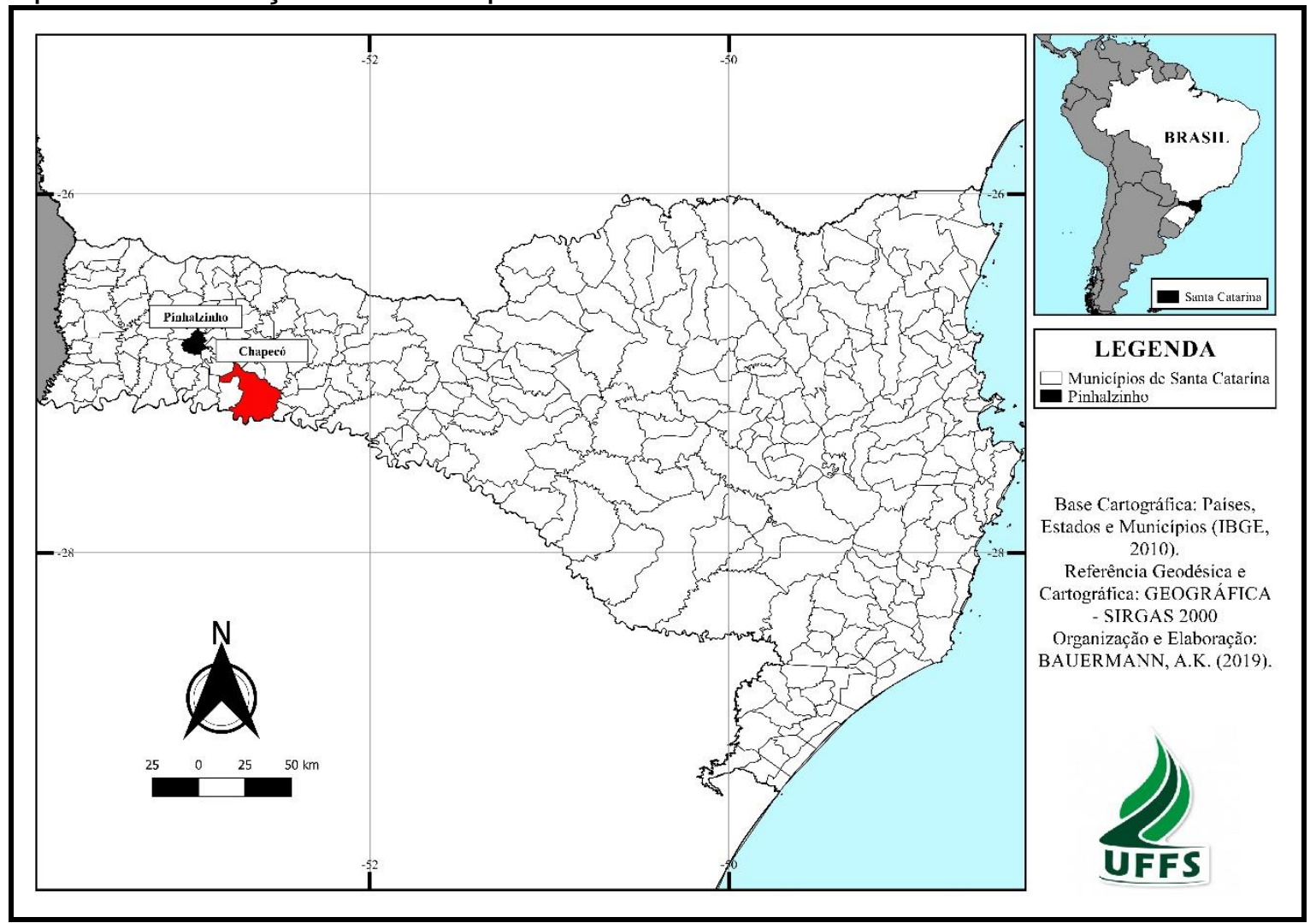

Fonte: IBGE (2010).

A paisagem foi escolhida como categoria de análise, pois, a ação dos homens sobre o espaço com espacialidades, temporalidades e culturas distintas, imprimem sobre ela marcas singulares, (re)constituindo-a e (re)significando-a. Ou seja, o espaço geográfico é a coexistência do passado, do presente ou de um tempo passado reconstituído no presente (SUERTEGARAY, 2001). Para Lisboa (2008), o homem é o agente por excelência do espaço geográfico, pois quando se verifica a interação entre o homem e o meio em que vive, do qual retira o que lhe é necessário para a sobrevivência, este promove alterações em suas características originais. A compreensão destas transformações do espaço é essencial para entendermos a paisagem sob uma ótica geográfica como "[...] o conjunto de formas que, num dado momento, exprimem as heranças que representam as sucessivas relações localizadas entre homem e natureza" (SANTOS, 2006, p. 66). Assim, "[...] cada paisagem se caracteriza por uma dada distribuição de formas-objetos, providas de um conteúdo técnico específico" (SANTOS, 2006, p. 67).

Nesta perspectiva a paisagem, determinada pelas formas preexistentes, consiste no resultado da acumulação de atividades que apresentam uma imbricada relação envolvendo diversas ações e objetos em variadas escalas temporais. Dessa maneira, a compreensão acerca da construção de uma paisagem não se trata mais 
em contentar-se com a descrição do meio ambiente no qual vivem e trabalham os homens, mas sim procura-se compreender as relações complexas estabelecidas entre os indivíduos e os grupos, as identidades que ali nascem e se desenvolvem, bem como ao ambiente que estes transformam (CLAVAL, 2004, p. 71). Assim, a paisagem pode ser percebida de acordo com Brunet citado por Claval (2004, p. 48) como:

aquilo que o olho abarca [...] de uma só olhadela, o campo do olhar. A paisagem é, portanto, uma aparência e uma representação [...]. Só é paisagem quando percebida. Alguns de seus elementos não aguardaram a humanidade para existir mas, se compõem uma paisagem, é sob a condição de serem olhados. Somente a representação os faz paisagem (grifos do autor).

A paisagem também se constitui de forma imaterial, ao representar determinados elementos como simbólicos por meio da memória dos homens, pois conforme aborda Schama (1996, p. 70) "a paisagem é cultura antes de ser natureza; um constructo da imaginação projetado sobre a mata, água, rocha”. Em vista disso, "os lugares não tem somente uma forma e uma cor, uma racionalidade funcional e econômica. Eles estão carregados de sentido para aqueles que os habitam ou que os frequentam" (CLAVAL, 2007, p.55). Por isso,

o espaço jamais aparece como um suporte neutro na vida dos indivíduos e dos grupos. Ele resulta da ação humana que mudou a realidade natural e criou paisagens humanas e humanizadas. Os lugares e as paisagens fazem parte da memória coletiva. A lembrança do que aconteceu no passado dá forte valor sentimental a certos lugares (CLAVAL, 2002, p. 24).

O estudo da paisagem, sob um viés histórico-geográfico também pode ser realizado com o auxílio da história ambiental ao passo que esta recompõe a memória social (CORRÊA, 2008) e discute historicamente os diferentes modos de interagir com o ambiente à medida que os conceitos, valores, concepções e práticas socioculturais são distintos ao longo da história e variam de região para região (NODARI, 2010), materializando-se nas paisagens. A história ambiental ao abranger uma grande variedade de assuntos pode ser agrupada em três níveis básicos, onde o primeiro abrange o entendimento da natureza propriamente dita, tal como se organizou e funcionou no passado; o segundo abarca discussões socioeconômicas, referentes ao modo de utilização dos recursos naturais pelos povos; e o terceiro nível, por sua vez, visa uma interação mais tangível e exclusivamente humana, puramente intelectual ou mental (WORSTER, 2003). 
E no Oeste, esse processo de transformações da paisagem passa a ser registrado com o uso de imagens principalmente a partir da colonização, que se inicia a partir do acordo de limites entre o Paraná e Santa Catarina em 1916 e o término da Guerra do Contestado (1912-1916). A partir de então passa a ocorrer o processo de partilha e concessão das terras devolutas a diversas companhias colonizadoras privadas, colocando, conforme Eunice Sueli Nodari (2009, p. 34) "em prática a opção de uma migração dirigida a grupos específicos que se adequassem aos padrões estabelecidos pelo governo estadual e por elas próprias, ou seja, que povoassem e colonizassem a região ordeiramente". Essa escolha para povoar a região de forma "ordeira" não incidiu sobre a população cabocla 4 , que já ocupava a região desde pelo menos o século $\mathrm{XIX}$, mas sim sobre os teutos e ítalo-brasileiros estabelecidos, ao longo do século XIX, nos núcleos de colonização do Rio Grande do Sul.

As terras eram concedidas as empresas em troca da construção de estradas, que na maioria das vezes beneficiava a própria colonizadora. Essas concessões também representavam uma:

política de povoamento e desenvolvimento de áreas desabitadas. Êste tipo de colonização depende, em grande parte, de fatôres políticos, que freqüentemente são instáveis e interferem com uma sã administração das colônias. Para uma companhia particular, colonização quer dizer negócio; ela quer ganhar dinheiro e é certo que o ganhará se conseguir uma boa qualidade de terra e gente também de boa qualidade. A administração se baseia estritamente em princípios econômicos e, em circunstâncias normais, não é prejudicada por interferência política. Esta é a razão pela qual as companhias particulares foram tão bem sucedidas na colonização do sul do Brasil, e Santa Catarina foi a região em que o princípio foi aplicado pela primeira vez em larga escala (WAIBEL, 1949, p.16).

No caso de Pinhalzinho, as terras foram comercializadas pela Companhia Territorial Sul Brasil, desde os anos 1930, conforme pode ser observado na figura 1. Essa figura consiste em um detalhe ampliado da planta Núcleos Coloniais, produzida pela Diretoria de Terras e Colonização do Estado de Santa Catarina na segunda metade da década de 1940.

\footnotetext{
${ }^{4}$ Seriam caboclos na definição de Paulo Pinheiro Machado (2004, p. 48), "os habitantes do planalto, ou seja, o habitante pobre do meio rural". Embora, conforme o autor, "não haja uma conotação étnica nesta palavra, freqüentemente o caboclo era mestiço, muitas vezes negro". Mas a principal característica desse conceito é que ele denota uma condição social e cultural, sendo os caboclos homens pobres que se dedicavam a agricultura, criação ou extrativismo, vivendo como sitiantes independentes nos interstícios das grandes fazendas pastoris, na maioria das vezes sendo posseiros, agregados ou peões.
} 
Figura 1- Núcleos de colonização do Médio e Extremo Oeste do estado de Santa Catarina, em 1940

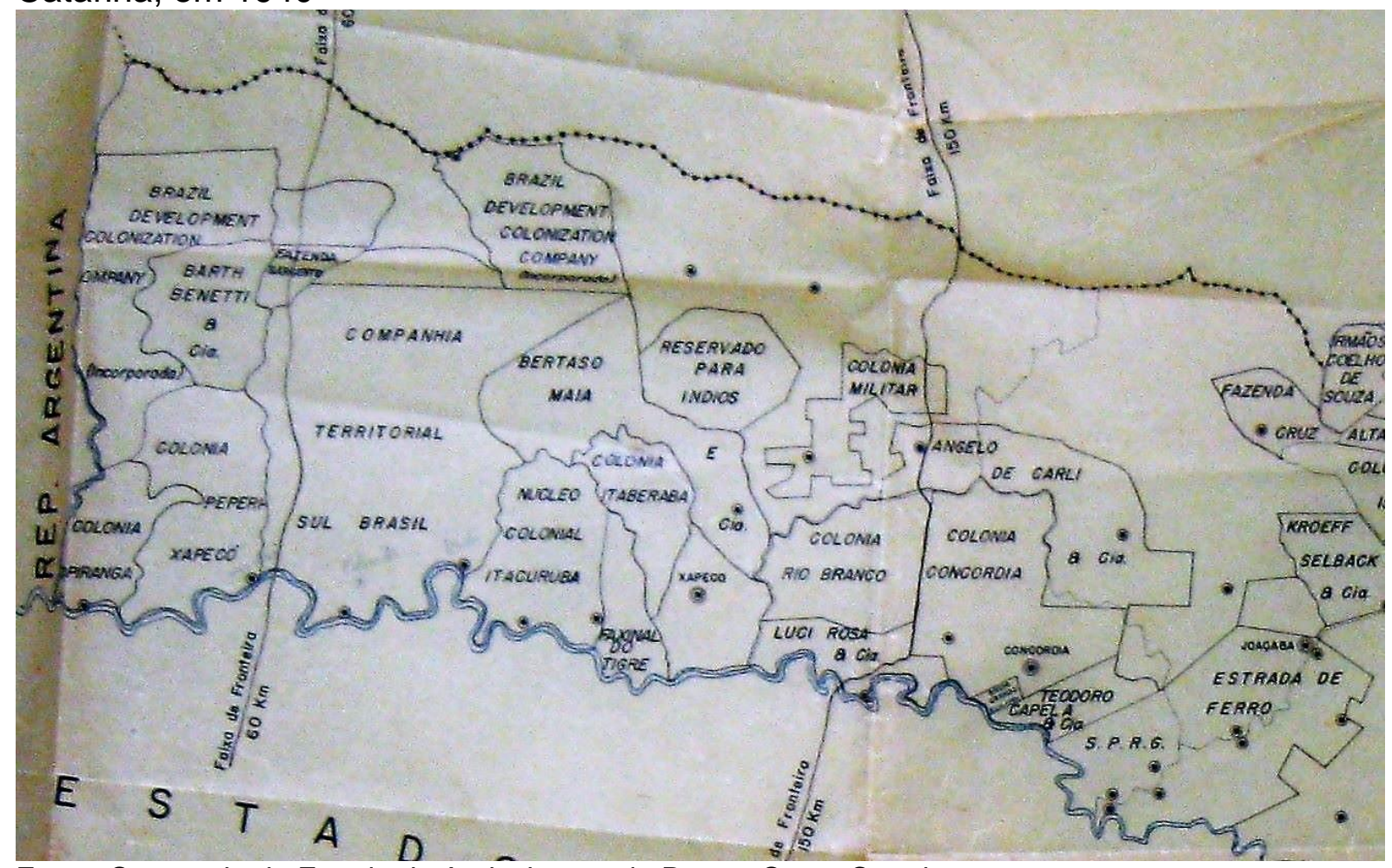

Fonte: Secretaria de Estado da Agricultura e da Pesca, Santa Catarina.

Não foram raras as situações envolvendo a relação entre posseiros e colonizadores a respeito da posse e do uso da terra em toda a região e também nas terras concedidas à Sul Brasil (WERLANG, 2006). Essa população cabocla vivia do extrativismo da erva-mate, da criação de animais à solta e compartilhando o espaço em comum (da caça, da pesca e da agricultura de subsistência) com moradores vizinhos (BRANDT E NODARI, 2011). O costume de criar animais soltos, por exemplo, deu origem aos primeiros atritos, como aponta Arlene Renk (1997, p. 107108):

Os conflitos se originariam por duas razões. A primeira, pela desvalorização, no mercado imobiliário, das terras próximas às dos intrusos, com a criação sem cerca [...]. Interessava à companhia o fim desta prática. A segunda razão, em nível de atitudes, seria a utilização das terras, isto é, com a agricultura rotativa. Uma utilização mais "racional" permitiria que diversas famílias, em exploração familiar, se valessem da área com resultados que, do ponto de vista do colonizador, seriam, seguramente, melhores.

Considerados intrusos em suas próprias terras, esses moradores experimentaram um processo de ruptura do seu antigo modo de vida com a inserção dessas novas atividades socioeconômicas, desestruturando formas costumeiras de 
uso e acesso à floresta e recursos naturais. Muitos desses moradores partiram em busca por novas terras, mais distantes, onde inevitavelmente seriam expulsos novamente ou passaram a trabalhar como assalariados em ervateira ou serraria local (BRANDT, 2017).

Em Pinhalzinho os primeiros migrantes chegaram em 1931, vindos de Selbach, no Rio Grande do Sul. Scatolin (2011, p.97) aponta que essas famílias, das quais destaca Manoel Klauck, Frederico Schneider e José Marcolino Eckert, vieram com o objetivo de construir uma serraria, devido às notícias de um denso pinhal, que circulavam na região. A autora ainda destaca que a partir do momento em que a notícia de terras férteis e de boa qualidade espalhou-se em Selbach, novas famílias vieram para trabalhar na serraria de José Marcolino Eckert. Neste sentido, Maria Eckert Utzig (2010, p.02), filha de José Marcolino, fazendo menção a seu pai, destaca que ele "[...] trazia pião lá de Selbach junto para trabalhar. Ele era acostumado como serrador lá onde nós morávamos, em Bela Vista; nós se criamos tudo em Selbach".

Dentre as serrarias instaladas nesse período, destacam-se as serrarias Campos, Eckert, Klauck e Scheneider e Pinhalzinho. Logo, ao constituírem as primeiras serrarias do município, foram responsáveis por efetuar uma "limpeza da área" a fim de possibilitar a expansão de áreas de produção agrícola, conforme aborda Eckert (2002). A importância da serraria fica evidente, pois:

No Pinhal ${ }^{5}$, a serraria trabalhava a todo vapor. Ali estavam radicadas poucas pessoas além das diretamente vinculadas ao empreendimento. [...] Nenhum morador tinha suas atividades voltadas só para a agricultura. Todos de uma forma ou de outra, permaneciam vinculados ao empreendimento madeireiro (ECKERT, 2002, p. 106).

A imagem que consta na figura 2 representa claramente os pressupostos apresentados, onde podemos perceber a atuação de uma serraria com a floresta devastada ao fundo. A imagem que data da década de 1950, retrata a primeira serraria do município, bem como o processo de limpeza da área para o estabelecimento de outras atividades.

\footnotetext{
${ }^{5}$ Primeira nomenclatura que o atual município de Pinhalzinho recebeu, quando este ainda era considerado uma vila. Cabe destacar que Pinhal passou a ser chamado de Pinhalzinho, pois os pinhais do município não eram tão densos quanto os colonizadores imaginavam. Para mais informações, ver Eckert (2002).
} 
Figura 2 - Serraria e floresta devastada ao fundo. Década de 1950

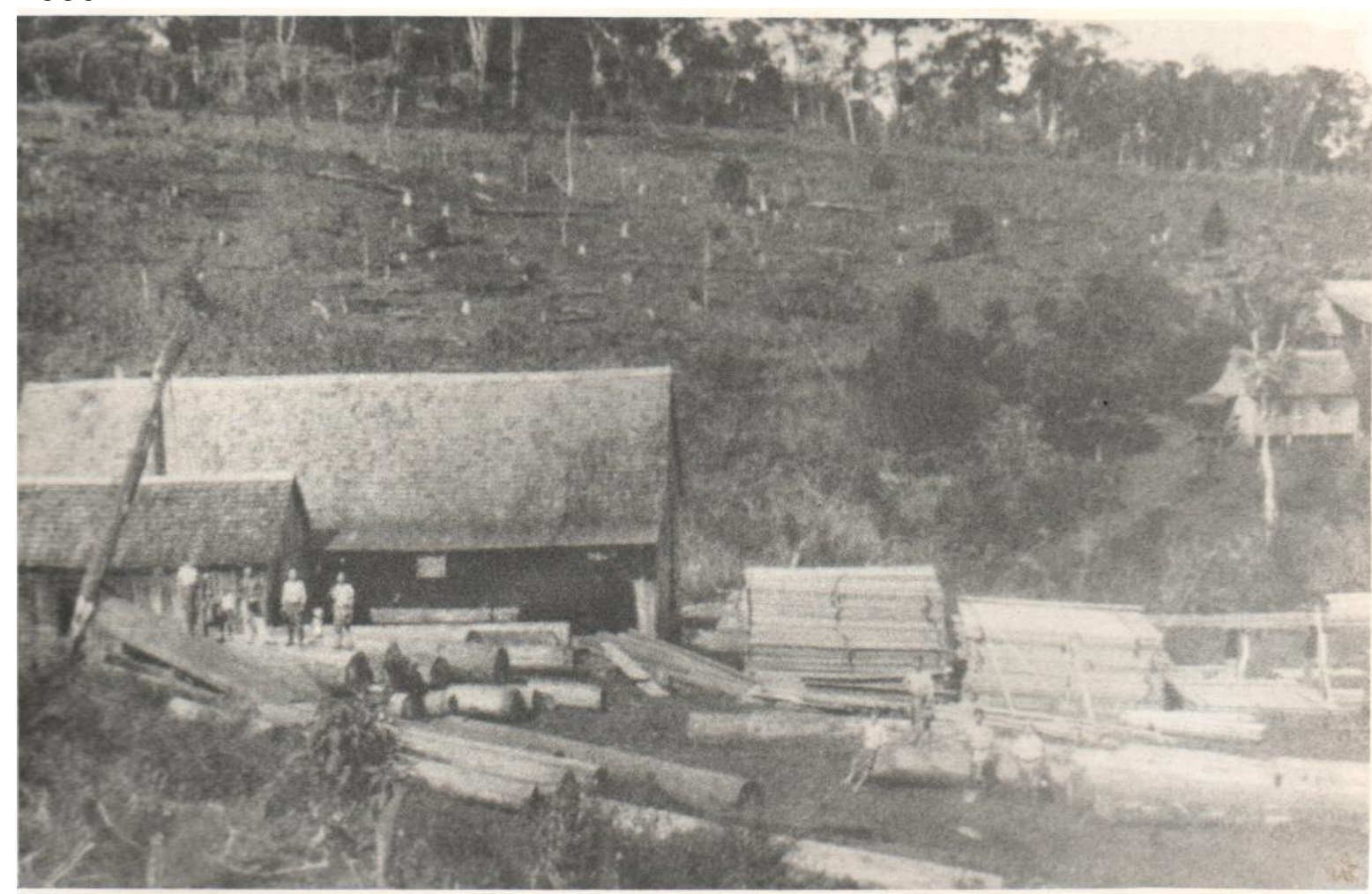

Fonte: Acervo Fotográfico do Museu Histórico de Pinhalzinho

Quanto ao funcionamento da serraria, Ivo Eckert (2011, p. 02), filho de um dos donos da serraria, frisa:

eu me lembro naquele tempo que nós éramos rodeados de floresta e o que mais me impressionava era os pinheiros, pinheiros muito grossos. Moramos naquele tempo e já tinha vindo cidadãos para trabalhar junto na serraria que o papai tinha construído, ali no Ivo Fiorini. Ao lado da sanga do Bonito, ali era a serraria. Para lá tinha que ser arrastadas às madeiras, as toras de pinheiros. Eu me impressionava com aquilo porque havia bois enormes, com chifres enormes, cinco, seis juntas para arrastar uma tora daquelas. As toras tinham a grossura que quase cobriam a altura de um homem. Então os bois, eles se ajoelhavam de tanta força que tinham que fazer. Os que guiavam os bois - João Utzig, Osvaldo Pinto, Alfredo Lauermann - eles na gritaria também, a cachorrada também fazia a sua arruaça e os bois, coitados, ajoelhados puxando as toras. Quando fosse um período de chuvas, com a terra molhada, a tora deslizava melhor. Nas secas - imagine só - então a tora era derrubada, descascada no local e se colocava no meio uma cunha de ferro, era colocada e fixada com martelo enorme e ali era engatado a corrente. A corrente era grossa, muito forte. Assim mesmo os bois às vezes rasgavam a corrente, os elos se abriam; prejudicavam. Era o que dava o primeiro problema - antes da madeira chegar na serraria - tinha que levar essa corrente para São Carlos onde tinha um soldador; aqui não existia nada disso. Aqui o que se não fazia na força bruta do homem, não era feito, qualquer tecnologia existia na Vila de São Carlos. Aqui não era nem vila, porque era um povoado e as pessoas viviam do que a natureza Ihes proporcionasse.

No contexto descrito evidencia-se a parceria estabelecida entre a colonizadora e as empresas madeireiras, pois, assim a área ficaria livre para as 
famílias de colonos trabalharem na terra, e as empresas extraírem a madeira (SOUZA, 2009). Portanto, depreende-se que a derrubada das matas já fazia parte do processo de colonização, uma vez que muitos dos colonos já haviam trabalhado com a exploração madeireira no Rio Grande do Sul.

Como não havia nenhum órgão governamental que fiscalizasse a retirada da madeira, esta foi feita de maneira indiscriminada (FROZZA, 2011, p.154). Hugo Campos (1990, p. 01), o qual era proprietário da Serraria Campos, que aparece na figura 3, conta:

até hoje eu comecei a vender lotes e os alemão me chamavam de louco, porque ali não dava loteamento, não dava nada e eu comecei a trabalhar lá. Botei uma serraria e enfim, fui povoando o lugar. [...] Eu comprei, primeiramente de um tal de Pedro Nolasco, 7 hectares de terra e depois comprei mais uns 20 hectares dos outros. [...] a terra não valia nada. Aí construí a Serraria. [...] a extração eu fazia. Botei plaina, botei tudo lá. E ia fazendo casas. E estrada não tinha. Nós fazia as estradas a custo de picareta. Tirando madeira e fazendo. Depois começou entrar colonos.

Figura 3 - Serraria Campos. Década de 1950

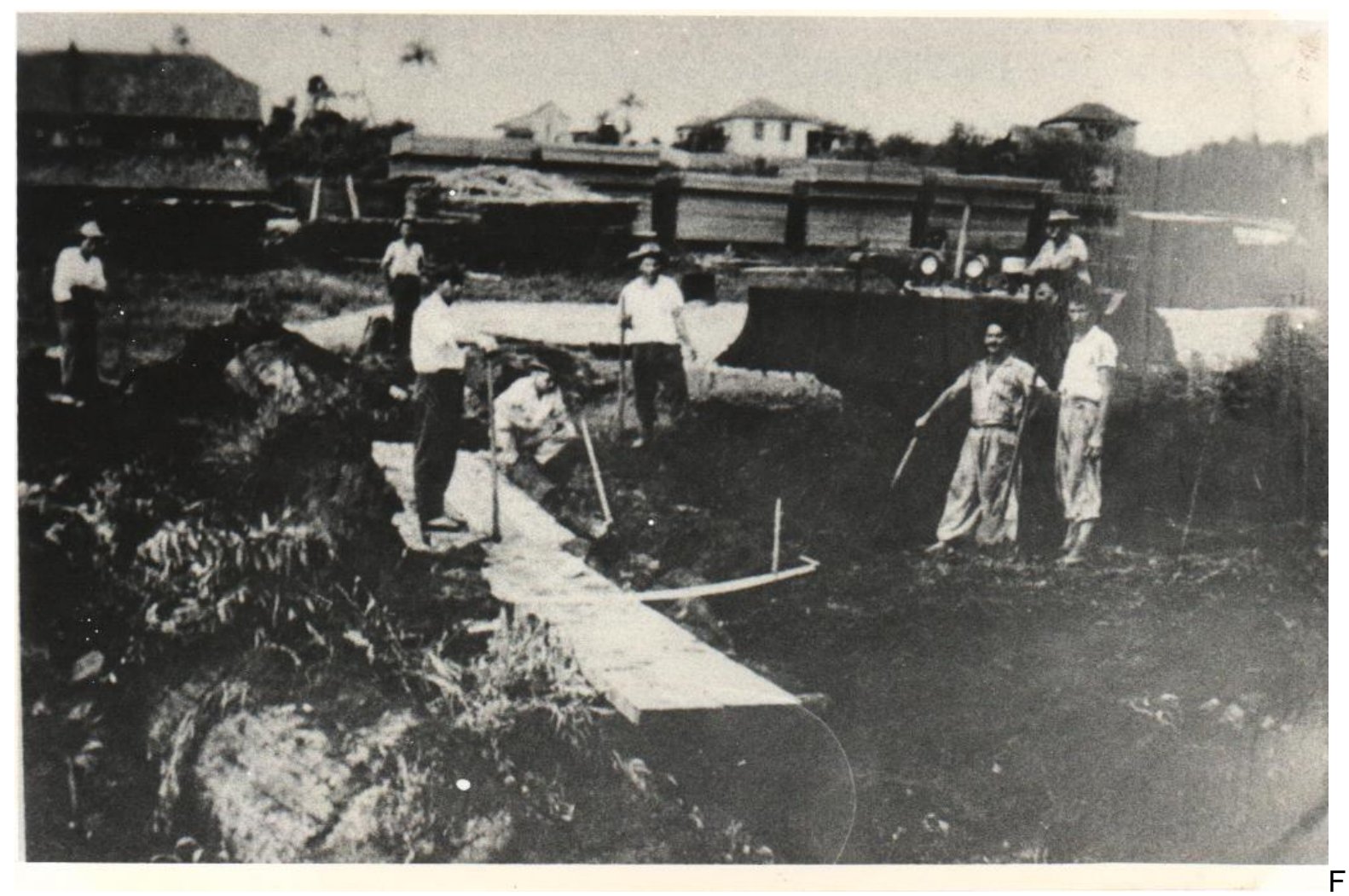

onte: Acervo Fotográfico do Museu Histórico de Pinhalzinho.

$\mathrm{Na}$ imagem podemos também observar o trabalho ainda braçal, com ferramentas simples e poucas máquinas. Ao fundo, notamos uma vila, que posteriormente viria a ser Pinhalzinho. A imagem da figura 4 reforça as serrarias 
enquanto elemento do traçado urbano da época. A serraria aparece no plano principal da imagem e é possível notar ao fundo um estoque de madeira. Analisando o ângulo e a estrutura da fotografia, têm-se a impressão de tratar-se da mesma serraria representada na figura 2. Ainda, verifica-se que Pinhalzinho, na época, distrito de São Carlos, ia desenvolvendo-se nas proximidades da serraria.

Figura 4 - Serraria e desenvolvimento do distrito de Pinhalzinho. Década de 1960

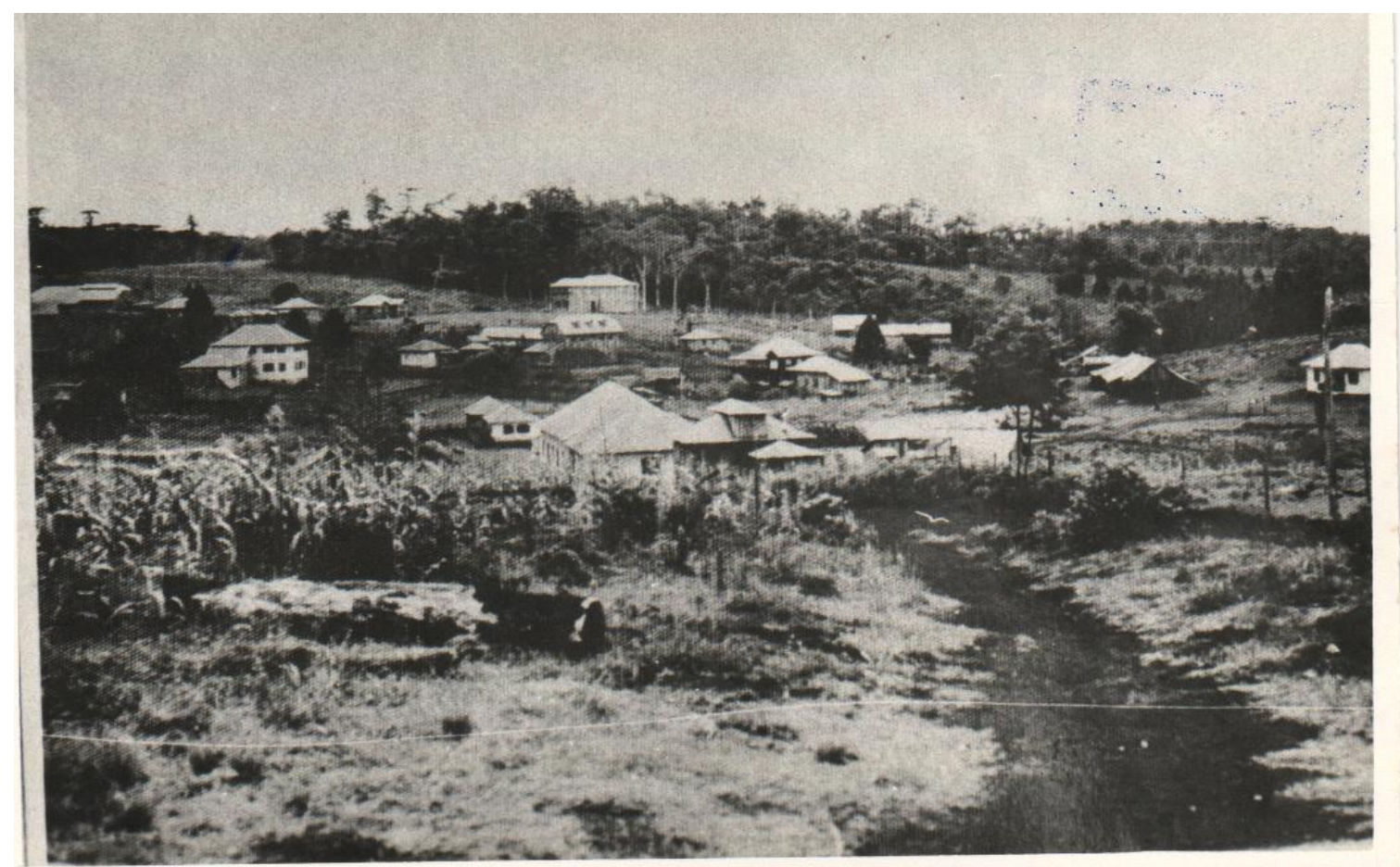

Fonte: Acervo Fotográfico do Museu Histórico de Pinhalzinho.

No que diz respeito ao destino das madeiras, Campos (1990, p. 02) enfatiza que "uma parte levei para Argentina. [...] O cedro que existia em Pinhalzinho foi tudo para a Argentina. O maior pecado do mundo". A madeira era transportada por meio de balsas, pelo rio Uruguai. Segundo relatos de Eckert (2011, p. 23);

[...] se a madeira ficava muito envolvida na água, ela apodrecia [...] nem todos os anos davam o ponto de balsa. O chamado ponto de balsa, que era a altura que o rio tinha que subir para poder passar o Salto do Rio Chapecó e o Salto Youcomã.

Por meio dos elementos expostos, nota-se que a atividade madeireira foi intensa ao longo das décadas de 1940 a 1970 no município de Pinhalzinho. A exploração madeireira propiciou que outras atividades econômicas se instalassem no município, proporcionando novas transformações da paisagem. No âmbito das novas atividades econômicas, que ocorriam em paralelo com a exploração 
madeireira, destacamos a atividade agrícola, a suinocultura e atividades comerciais e industriais.

Quanto à atividade agrícola, "na década de 1940, as lavouras já faziam parte da economia da pequena vila. Os produtos começaram a ter preço e mercado, surgindo os primeiros comerciantes. Chegavam sempre mais moradores. Derrubavam o mato com machado, plantavam milho e feijão" (FROZZA, 2011, p. 158). Nesse sentido, Schumartz $(2017$, p. 03,04) relata:

[...] quando o pai veio, praticamente tudo era mato. Tinha só uns cantinho aberto, daí eles foram abrindo mais, foram mexendo. [...] A evolução foi difícil, ainda, ainda que eles saíram do Rio Grande do Sul por que lá não dava mais nada, lá não produzia mais nada. Aí vieram pra Santa Catarina, abrir roça nos morro, que ali era terra forte. Lá no Rio Grande falavam que tinha que ser morro pra ser terra boa, que produzia sem nada. Aí a primeira roça do meu pai era morro e hoje se fosse falar, acham que é impossível. Depois foi aumentando, foi evoluindo, foi crescendo, a família foi aumentando e fomos abrindo mais terra.

Paralelamente a produção agrícola, desenvolveu-se a produção de suínos. A figura 5 mostra suínos sendo criados em cercados de madeira, também conhecidas como mangueiras. Nesse sentido, a produção local era comprada inicialmente pelos comerciantes, depois os animais eram fechados em cercados de madeira e quando a carga estivesse completa, era transportada para os frigoríficos em Videira ou Chapecó (FROZZA, 2011, p. 161). 
Figura 5 - Suínos criados no cercado de madeira na propriedade do comerciante Jorge da Silva na década de 1950.

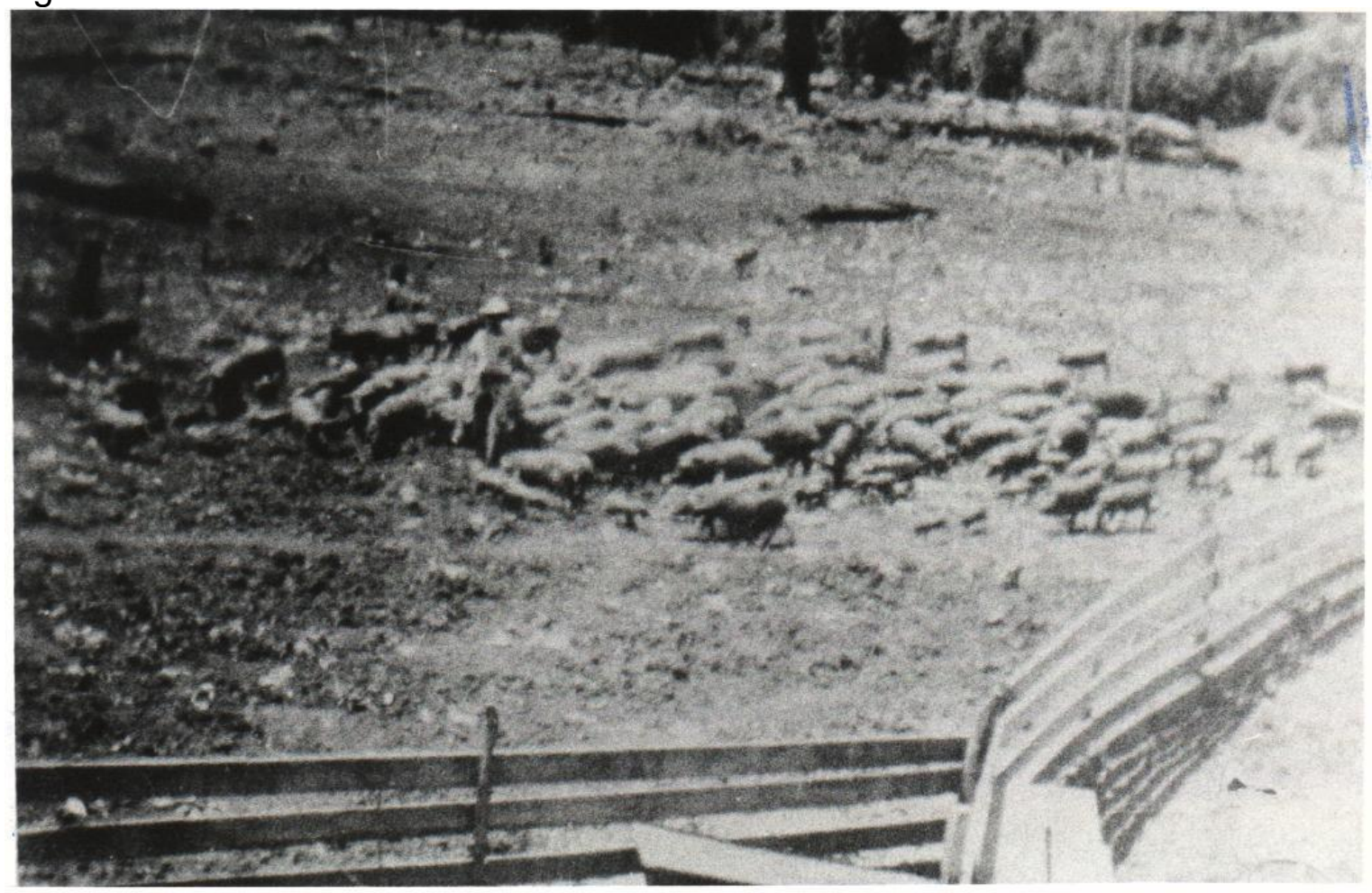

Fonte: Acervo Fotográfico do Museu Histórico de Pinhalzinho.

No Oeste em geral, o desenvolvimento e expansão do processo de colonização deu origem a uma série de pequenos quadros urbanos que serviam para atender as necessidades locais, fator esse que motivou a vinda de pequenos artesãos, padeiros, sapateiros e comerciantes para a região (ESPÍNDOLA, 1999; SOUZA, 2012). Em Pinhalzinho, com o crescimento da vila, associado à intensificação das atividades madeireiras, agrícolas e da criação de suínos, houve a instalação dos primeiros comércios, que atuavam na compra e venda de cereais, suínos e a venda de produtos de varejo. Segundo Frozza (2011), no que diz respeito à atividade industrial, têm-se na implantação das serrarias as primeiras atividades industriais. Além das madeireiras, outras atividades merecem destaque como a fabricação de telhas na década de 1950 pela Cerâmica Floss e a instalação de uma fábrica de refrigerantes em 1957.

Por meio do contexto descrito pode-se compreender o processo de colonização como uma ruptura propulsora da mudança da paisagem, onde a floresta passa a servir como produtora de mercadorias para a reprodução de uma sociedade capitalista. Ao chegarem a Pinhalzinho, os colonizadores, nas palavras de Eckert, reproduzindo o discurso da abundância de recursos e da virtude étnica na superação das adversidades e o aproveitamento "correto" dessa riqueza 
"encantaram-se com a abundância de madeiras de lei, a terra vermelha para o plantio de cereais, as frutas nativas que mais pareciam um pomar a céu aberto e a quantidade de caça" (ECKERT, 2002, p.55). Enquanto a colonizadora perseguia seu objetivo de transformar a região em um celeiro agrícola, aos primeiros sócios das empresas madeireiras o que interessava era a madeira, principalmente a araucária (ECKERT, 2002, p.56).

Desta maneira, se pode perceber que a devastação da floresta, dentro desse contexto de parceria entre a colonizadora e as empresas madeireiras, era vista como um símbolo do "progresso", aproveitando o que nas suas visões não era utilizado pela população cabocla.

Mediante todas as discussões apresentadas, é possível perceber a forma como as relações estabelecidas entre o homem e a natureza se modificaram ao longo dos anos, ou seja, (re) significaram e (re) constituíram a paisagem do município de Pinhalzinho. O processo de colonização agiu, portanto, como uma ruptura propulsora da mudança da paisagem, onde a floresta passou a servir como produtora de mercadorias para a reprodução de uma sociedade capitalista.

Para finalizar, abordar a paisagem como um documento geográfico, por meio de fotografias, constitui-se como uma prática de suma importância, ao passo que permite ler as relações entre os homens e a natureza, integrando as características e os elementos físicos e humanos, tanto do passado, quanto suas heranças no presente.

\section{REFERÊNCIAS}

BRANDT, Marlon; NODARI, Eunice Sueli. Comunidades tradicionais da Floresta de Araucária de Santa Catarina: territorialidade e memória. História Unisinos. São Leopoldo, v. 15, n. 1, p. 80-90, 2011.

BRANDT, Marlon. Paisagens caboclas no Oeste de Santa Catarina: colonização e rupturas. In: BRANDT, Marlon; NASCIMENTO, Ederson. (Orgs.). Oeste de Santa Catarina: território, ambiente e paisagem. São Carlos: Pedro e João, 2015.

. Paisagem e uso comum da Floresta Ombrófila Mista pela população cabocla do

Oeste de Santa Catarina. In: GERHARDT, Marcos; NODARI, Eunice Sueli; MORETTO,

Samira Peruchi (Orgs.). História ambiental e migrações: diálogos. São Leopolido: Oikos; Chapecó: UFFS, 2017.

BRUNET, Roger (org). Les Mots de La Geographie, Dictionnaire Critique. Paris/ Montpellier: La Documentation Française/ Reclus, 1992.

CLAVAL, Paul. A geografia cultural. 3. ed. Florianópolis: Editora da UFSC, 2007. 453 p. . A paisagem dos geógrafos. In: CORRÊA, Roberto Lobato; ROSENDAHL, Zeny

(orgs) Paisagens textos e identidade. Rio de Janeiro: Ed UERJ, 2004.

"A volta do cultural" na Geografia. Mercator: Revista de Geografia da UFC,

Fortaleza, v. 1, n. 1, p.19-28, 2002. Disponível em: 
http://www.mercator.ufc.br/index.php/mercator/article/viewArticle/192. Acesso em: 02 abr. 2018.

CORRÊA, Dora Shellard. Descrições de paisagens: construindo vazios humanos e territoriais indígenas na capitania de São Paulo ao final do século XVIII. Varia História, Belo Horizonte, v. 24, n. 39, 2008 p.135- 152.

ECKERT, Ivo. Bonito pinhal Pinhalzinho: a saga dos pioneiros. Florianópolis: Gráfica Floriprint, 2002. 212 p.

ESPÍNDOLA, Carlos Jose. As agroindústrias no Brasil: O caso Sadia. Chapecó: Editora Grifos; 1999.

FROZZA, Ires. Retratos da formação socioeconômica de Pinhalzinho. In: BEN, Fernanda et al. Retratos, memórias e fragmentos da história de Pinhalzinho/SC. Pinhalzinho:

Schaefer, 2011. Cap. 4. p. 153-180.

GERHARDT, Marcos. Imagens, natureza e colonização no Sul do Brasil. In ARRUDA,

Gilmar (org.). Natureza, fronteiras e territórios: imagens e narrativas. Londrina: Eduel, 2005.

Instituto Brasileiro de Geografia e Estatística (IBGE). Disponível em:

<https://www.ibge.gov.br/>. Acesso em: 02 ago. 2018.

LISBOA, Severina Sarah. A IMPORTÂNCIA DOS CONCEITOS DA GEOGRAFIA PARA A APRENDIZAGEM DE CONTEÚDOS GEOGRÁFICOS ESCOLARES. Revista Ponto de Vista, Viçosa, v. 4, p.23-35, 2007.

MACHADO, Paulo Pinheiro. Lideranças do Contestado: a formação e a atuação das chefias caboclas (1912-1916). Campinas: Ed. da Unicamp, 2004.

NODARI, Eunice Sueli. Etnicidades renegociadas: práticas socioculturais no Oeste de Santa Catarina. Florianópolis: Ed. da UFSC, 2009. Um olhar sobre o Oeste de Santa Catarina sob o viés da história ambiental.

História: Debates e Tendências, Passo Fundo, v. 9, n. 1, p.136-150, 2010.

Prefeitura Municipal de Pinhalzinho. História. Disponível em:

http://www.pinhalzinho.sc.gov.br/historia. Acesso em: 20 ago. 2018.

RENK, Arlene Anélia. A luta da erva: um ofício étnico no Oeste catarinense. Chapecó: Grifos, 1997.

A Luta da erva: um ofício étnico da nação brasileira no Oeste Catarinense. 2. Ed. Rev. Chapecó: Argos, 2006.

SCATOLIN, Leocádia Pavan. Pinhalzinho: aspectos geográficos, história e educação. In: BEN, Fernanda et al. Retratos, memórias e fragmentos da história de

Pinhalzinho/SC. Pinhalzinho: Schaefer, 2011. Cap. 3. p. 89-152.

SANTOS, Milton. A Natureza do Espaço: Técnica e Tempo. Razão e Emoção. 4. ed. São Paulo: Editora da Universidade de São Paulo, 2006. 259 p.

SCHAMA, Simon. Paisagem e memória. São Paulo: Companhia das Letras, 1996.

SOUZA, Joel José de. Gênese e evolução da indústria de laticínios do oeste de Santa

Catarina. 120 f. Dissertação (Mestrado) - Universidade Federal de Santa Catarina, Centro de Filosofia e Ciências Humanas, Programa de Pós-Graduação em Geografia, Florianópolis, 2009.

SUERTEGARAY, Dirce Maria Antunes. Espaço geográfico uno e múltiplo. Scripta Nova:

Revista Electrònica de Geografia y Ciências Sociales, Barcelona, v. 5, n. 93, p.01-08, 15 jul. 2001. Disponível em: http://www.ub.edu/geocrit/sn-93.htm. Acesso em: 21 abr. 2016.

WAIBEL, Leo. Princípios da Colonização Européia no Sul do Brasil. Revista Brasileira de Geografia, Rio de Janeiro, v. 2, n. 11, p.03-58, jun. 1949. Disponível em:

http://biblioteca.ibge.gov.br/visualizacao/periodicos/115/rbg_1949_v11_n2.pdf. Acesso em: 20 mar. 2018.

WERLANG, Alceu Antonio. Disputas e ocupação do espaço no oeste catarinense: a atuação da Companhia Territorial Sul Brasil. Chapecó: Argos, 2006. 149 p.

WORSTER, Donald. Transformações da terra: para uma perspectiva agroecológica na História. Ambiente \& Sociedade. Campinas, v. V, n. 2, ago-dez. 2002. v. VI, n. 1, jan-jul. 2003, p. 25.

ZENDRON, Rute Coelho. O fotógrafo. Esboços. V.10, p. 84-95, Chapecó, 2002.

ENTREVISTAS 
CAMPOS, Hugo. Entrevista concedida a Ires Frozza. Acervo de História Oral do Museu Histórico de Pinhalzinho/SC. Pinhalzinho/SC, 1990.

ECKERT, Carlos Eugênio. Entrevista concedida a Fernanda Ben. Acervo de História Oral do Museu Histórico de Pinhalzinho/SC. Pinhalzinho/SC, 2011.

SCHMATZ, João Alfredo. 50 anos. Depoimento, 15 ago. 2017. Pinhalzinho/SC.

Entrevistadora: Andressa Krieser Bauermann. Acervo do projeto de extensão Memória histórico-geográfica do Planalto e Oeste de Santa Catarina: imagens e oralidades.

UTZIG, Maria Eckert. Entrevista concedida a Fernanda Beme Leocádia Scatolin. Acervo de História Oral do Museu Histórico de Pinhalzinho/SC. Pinhalzinho/SC, 2010.

\section{NOTAS DE AUTOR}

\section{CONTRIBUIÇÃO DE AUTORIA}

Andressa Krieser Bauermann - Coleta de dados, Análise de dados, Concepção e elaboração do manuscrito, Participação ativa da discussão dos resultados; Revisão e aprovação da versão final do trabalho

Marlon Brandt - Análise de dados, Concepção e elaboração do manuscrito, Participação ativa da discussão dos resultados, Revisão e aprovação da versão final do trabalho.

\section{FINANCIAMENTO}

Universidade Federal da Fronteira Sul (bolsa). Projeto aprovado no Edital 281/UFFS/2015.

\section{CONSENTIMENTO DE USO DE IMAGEM}

Não se aplica (museu).

\section{APROVAÇÃO DE COMITÊ DE ÉTICA EM PESQUISA}

Não se aplica.

\section{CONFLITO DE INTERESSES}

Não se aplica.

\section{LICENÇA DE USO}

Este artigo está licenciado sob a Licença Creative Commons CC-BY. Com essa licença você pode compartilhar, adaptar, criar para qualquer fim, desde que atribua a autoria da obra.

\section{HISTÓRICO}

Recebido em: 10-08-2018

Aprovado em: 29-08-2019 